\title{
Super Antibiotics: Part III. Hyperforin, Revision of the Relative and Absolute Stereochemistry Presented by Bystrov et al.
}

\author{
Ilia Brondz \\ Norwegian Drug Control and Drug Discovery Institute (NDCDDI), Ski, Norway \\ Email: ilia.brondz@gmail.com
}

How to cite this paper: Brondz, I. (2017) Super Antibiotics: Part III. Hyperforin, Revision of the Relative and Absolute Stereochemistry Presented by Bystrov et al. Voice of the Publisher, 3, 15-24.

https://doi.org/10.4236/vp.2017.32002

Received: May 16, 2017

Accepted: June 24, 2017

Published: June 27, 2017

Copyright $\odot 2017$ by author and Scientific Research Publishing Inc. This work is licensed under the Creative Commons Attribution International License (CC BY 4.0).

http://creativecommons.org/licenses/by/4.0/

\section{(c) (i) Open Access}

\begin{abstract}
Hyperforin is an antibiotic, antibacterial, antiprotozoal, antiviral, anticancer, and immunomodulatory substance. It is possibly a new and potent tool for curative treatment of a broad array of infection diseases. Despite the medical usefulness of Hypericum perforatum L., which has been known since ancient times, its constituents were not well studied until the middle of the $20^{\text {th }}$ century. Several pharmacological active substances (PASs) were then discovered as constituents of $H$. perforatum. Among these was the antibacterial substance, hyperforin. The chemistry and relative and absolute stereochemistry of hyperforin were studied at the Shemyakin Institute of Bioorganic Chemistry, USSR Academy of Sciences, Moscow, USSR, the Institute of Biochemistry and Physiology of Microorganisms, USSR Academy of Sciences, Moscow, USSR, and the Zabolotny Institute of Microbiology and Virology at the Ukrainian Academy of Sciences, Kiev, UkrSSR. In this paper, hyperforin's relative and absolute stereochemistry, as reported in earlier published former USSR literature (cited herein), is discussed, as well as cited up to date in international literature. In 1979, the relative and absolute stereochemistry of hyperforin and some constituents of $H$. perforatum were studied at the University of Oslo, Oslo, Norway. In 1979, Brondz et al. challenged the correctness of the relative and absolute stereochemistry of hyperforin reported previously by Bystrov et al. The relative stereochemistry of a drug is the basis for possible partial or total synthesis and absolute stereochemistry is crucial for the action of drugs on enzymes. Correct molecular isometry (absolute stereochemistry) is key for high pharmacological activity versus harm/toxicity. Elucidation of the stereochemistry of an unknown molecule is of great academic and theoretical interest, and in the case of a drug, it also has great practical interest.
\end{abstract}

\section{Keywords}

Antibiotics, Hyperforin, Super Antibiotic, Fifth-Generation Antibiotic, Revision of Relative and Absolute Stereochemistry 


\section{Introduction}

Evidence and knowledge of the medical value of Hypericum perforatum L. ${ }^{1}$ in ancient times are contained in the writings of Galen, Dioscorides, Pliny, and Hippocrates. In the middle of the $20^{\text {th }}$ century, Osborn published a review [1] in which he described the occurrence of an antibiotic substance in $H$. perforatum. In the former USSR, many publications addressed the biological activity of extracts from H. perforatum [2] [3] [4] [5].

In 1975, Bystrov et al. [6] described the structure of hyperforin, which is the principal pharmacological active substance (PAS) in $H$. perforatum. Further publications on the same topic followed until the end of 1978 [7] [8] [9] [10] [11]. There were some conflicting findings and inconsistencies [6]-[11]. Thus, Brondz et al., and Brondz [12]-[22], at the University of Oslo, Oslo, Norway, decided to challenge the relative and absolute stereochemistry of hyperforin as described in [6], [10], [11], and which describe the content and biological activity of $H$. perforatum and the stereochemistry of the main PAS, hyperforin. This paper is the third in a series of papers, "Super Antibiotics" [21], [22]. It should offer some clarity on the longstanding differences in the presentation of the relative and absolute stereochemistry of hyperforin.

\subsection{Known Facts Prior to the Publication of Bystrov et al. Structures Reported 1975-1978}

As mentioned in the Introduction, the pharmacological usefulness of $H$. perforatum has been described by Galen, Dioscorides, Pliny, and Hippocrates. The usefulness of $H$. perforatum in the Middle Ages has also been reported. More recently, in the middle of the $20^{\text {th }}$ century, antibacterial properties of the drug were considered [1] [2] [3] [4] [5]. In 1975, Bystrov et al. reported that the PAS in $H$. perforatum is hyperforin, and they further described hyperforin's structure and the stereochemistry (Figure 1) [6].
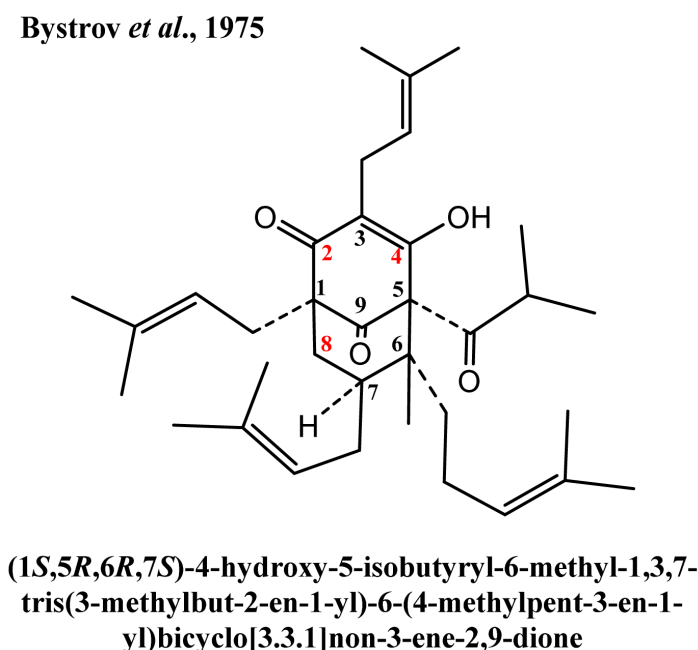

Figure 1. The structure of hyperforin reproduced from [6] (The author of this paper has added numbers in red and the IUPAC name of the substance for better understanding).

${ }^{1}$ Hyperforin, Revision of the Relative and Absolute Stereochemistry. 


\subsection{Challenging the Relative and Absolute Stereochemistry as Published by Bystrov et al.}

In the very early days of scientific chemistry, several important criteria were established for elucidation of the chemistry of unknown molecules: atom composition (qualitative and quantitative), molecular weight (MW), structure, and stereochemistry. As ultimate evidence for the correct elucidation of the chemistry and stereochemistry of an unknown molecule was the synthesis of a substance that complied with the nature of the molecule under investigation. A correct hypothesis about the structure was accepted also based on X-ray crystallography. However, the last word in confirming correctness was left to the de novo synthesis of the unknown molecule and comparison of its nature with the molecule under investigation. Only if all parameters of the unknown molecule and the synthetically prepared analog are in compliance, and the identity of the two molecules is established, can the structure of the unknown molecule, be claimed as known. This is especially important in the case of isomeric molecules and molecules with chirality. Partial degradation of a molecule that is under investigation and spectral comparison with known molecules can lead to errors because the degradation can affect the chirality of the resulting substance in relation to the chirality of the molecule under investigation. Here, it is important to note that $R$ and $S$ chirality has no direct reflection on or relation with the + or - signs: “... the $(+) /(-)$ system has no fixed relationship with the $(R) /(S)$ system" [23]. Hence, claiming as evidence that a molecule is + or - does not tell us enough about the " $(R) /(S)$ system" state of chiral centers.

According to Bystrov et al. [6]: “... the antibiotic, Hyperforin, is therefore the $6 S, 7 R$ configuration" and, furthermore, "Therefore the trans configuration has been assigned to the hydroxyl (and consequently to the angular C-1 and C-5 side chain) with respect to the 6-methyl group, as shown in formula I" [6]. In the present paper, formula I is reproduced as Figure 1. It is later stated in [6] that "Independent proof of the absolute configuration I was furnished by the CD spectrum of III which, like that of $5 S$-spiro-[4,4]-nonane-1,6-dione”. Considering the statements in [6], the chirality of centers 5,6 , and 7 should be $S, S$, and $R$, respectively. However, following the formula I, reproduced as Figure 1, the chirality is $5 R, 6 R$, and $7 S$ as it should be when following IUPAC nomenclature. In their following publications about the stereochemistry of antibiotic hyperforin [10] and [11], the authors of [6] changed the numbering of the $\mathrm{C}$ atoms in the bicyclic system, and consequently the stereochemistry and the chirality (see Figure 2).

In [10], the authors have not presented the chirality of the molecule; however, in [11], the absolute stereochemistry was already presented based on a new numbering of the $\mathrm{C}$ atoms earlier published in [10] (see Figure 3).

Following the logic of the numbering presented by Bystrov et al. in [11], the name and chirality should beas follows: $(1 R, 5 S, 7 S, 8 R)$-2-hydroxy-1-isobutyryl-8-methyl-1,3,7-tris(3-methylbut-2-en-1-yl)-8-(4-methylpent-3-en-1-yl)bicycl $\mathrm{o}$ [3.3.1] non-3-ene-4,9-dione. However, in text of [11], the chirality is given for 


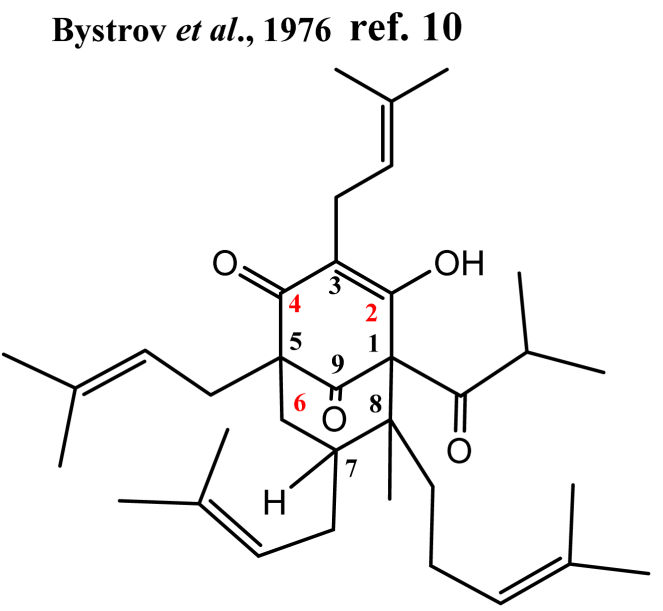

\section{2-hydroxy-1-isobutyryl-8-methyl-3,5,7-tris (3-methylbut-2-en-1-yl)-8-(4-methylpent- 3-en-1-yl)bicyclo[3.3.1] non-3-ene- 4,9-dione}

Figure 2. The structure of hyperforin reproduced from [10] (The author of this paper has added numbers in red and the IUPAC name of the substance for better understanding).

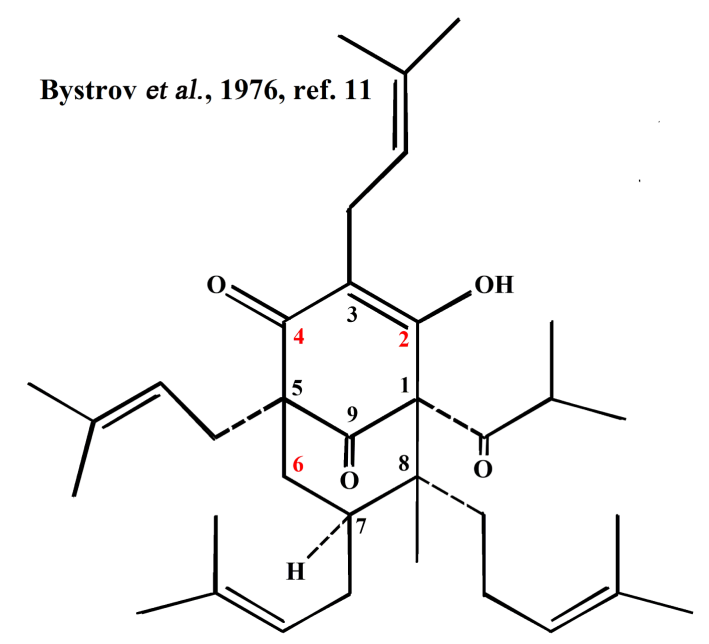

Figure 3. The structure and stereochemistry of hyperforin reproduced from [11] (The author of this paper has added numbers in red for better understanding).

C-7 and C-8 as $R$ and $S$, respectively. Concerning the chirality of C-5, there exists many conflicting explanations. It is nonetheless possible to extract the conclusion that the authors designated it as $5 S$-spiro[4,4]-nonane-1,6-dione, which means that C-5 has chirality $S$. However, following the IUPAC rules for this structure presented in [11], the numbering and chirality of this structure should be as follows: $\quad(1 S, 5 R, 6 R, 7 S)$-4-hydroxy-5-isobutyryl-6-methyl-1,3,7-tris(3-me-thylbut2-en-1-yl)-6-(4-methylpent-3-en-1-yl)bicyclo[3.3.1]non-3-ene-2,9-dione.

Figure 4 and Figure 5 present diagrams in which the construction of a name following the IUPAC rules for bicyclic compounds are demonstrated for a simpler understanding. 
<smiles>C1CCCCC1</smiles>

cyclohexane

1<smiles>C1CC2CCCC(C1)C2</smiles>

bicyclo[3.3.1]nonane<smiles>CC=C(C)C</smiles>

2-methylbut-2-ene

2<smiles>C1=CC2CCCC(C1)C2</smiles>

6

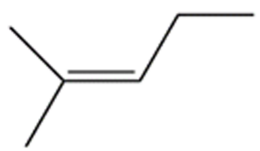

2-methylpent-2-ene

3<smiles>CC(C)C=O</smiles>

isobutyraldehyde

4

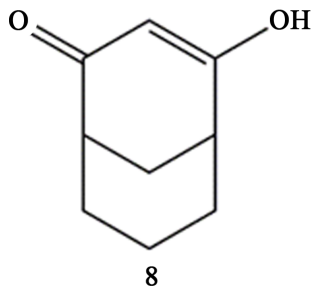

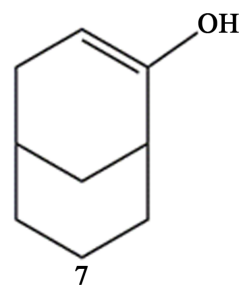

bicyclo[3.3.1]non-2-en-2-ol 4-hydroxybicyclo[3.3.1] non-3-en-2-one

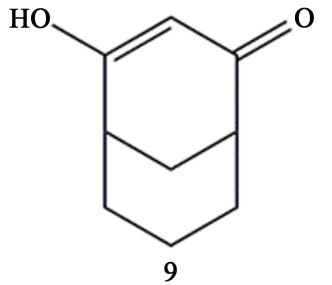

4-hydroxybicyclo[3.3.1] non-3-en-2-one<smiles>O=C1C=C(O)C2CCCC1C2=O</smiles>

4-hydroxybicyclo[3.3.1]non3-ene-2,9-dione<smiles>CC(C)C(=O)C12C=C(CC=CC1)C(=O)C=C2O</smiles>

4-hydroxy-5-isobutyrylbicyclo [3.3.1]non-3-ene-2,9-dione<smiles></smiles>

4-hydroxy-1-isobutyrylbicyclo [3.3.1]non-3-ene-2,9-dione

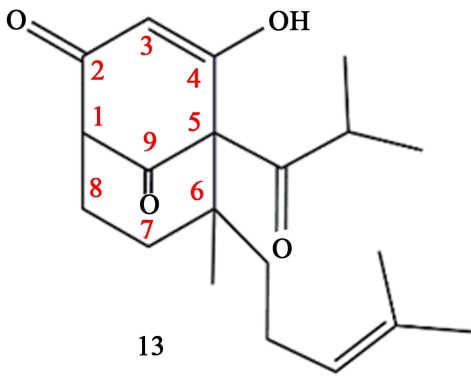

4-hydroxy-5-isobutyryl-6-methyl-6-(4methylpent-3-en-1-yl)bicyclo[3.3.1]non3-ene-2,9-dione

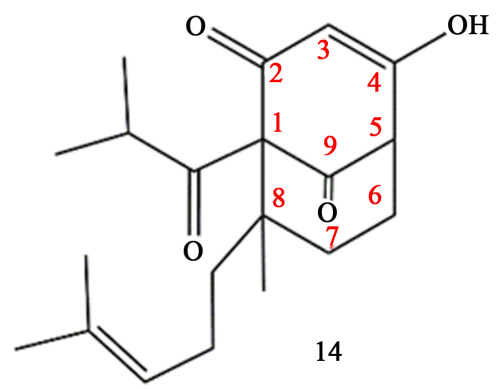

4-hydroxy-1-isobutyryl-8-methyl-8-(4methylpent-3-en-1-yl)bicyclo[3.3.1]non3-ene-2,9-dione

Figure 4. Explanation for construction of names and numbering of $\mathrm{C}$ atoms for bicyclic compounds following IUPAC rules. Compounds 8 and 9 are the same molecules; however, compounds 11 and 12 differ because they are isomers. Compounds 13 and 14 are also isomers.

\section{Discussion}

Upon inspection of [6] with [10], and [11], it is evident that the figures that should support the stereochemistry of hyperforin differ (see Figure 6). Numbering of the chiral carbons also differs. It is noted that in [6] and [11], the same stereochemical expression for hyperforin is presented. However, the authors state in [6] that it has a configuration of $6 S$ and $7 R$, whereas they state in [11] that it has a configuration of $7 R$ and $8 S$. In both papers, the description of the configuration of C-1 and C-5 is rather unclear; the conclusions are only made based on figures presented in [6] and [11]. However, numbering of the carbons 


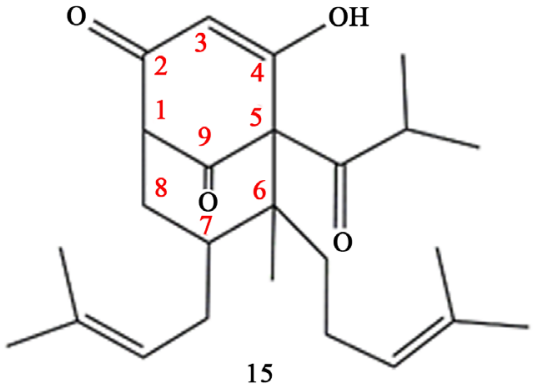

4-hydroxy-5-isobutyryl-6-methyl-7-(3-(methylbut-2-en-1-yl)-6-(4methylpent-3-en-1-yl)bicyclo[3.3.1]non-3-ene-2,9-dione

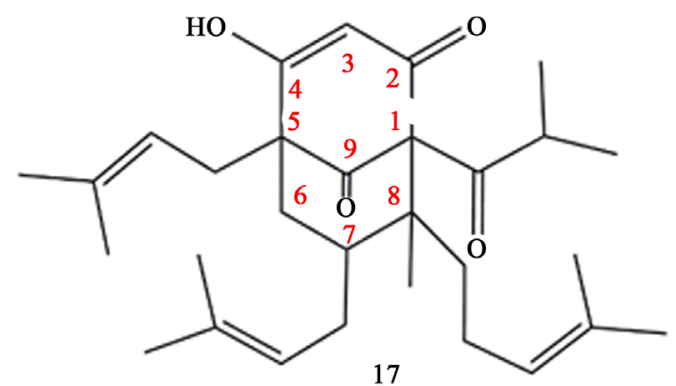

4-hydroxy-1-isobutyryl-8-methyl-5,7-bis (3-methylbut-2-en-1-yl)-8-(4-methylpent3-en-1-yl)bicyclo[3.3.1]non-3-ene-2,9-dione

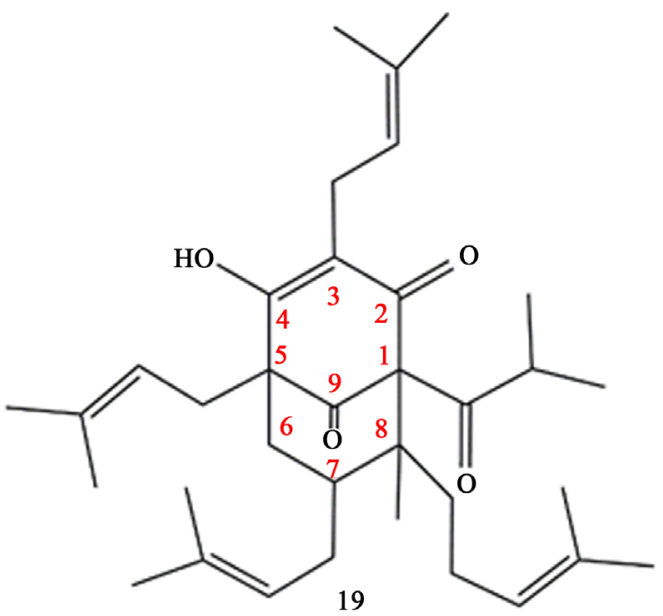

4-hydroxy-1-isobutyryl-8-methyl-3,5,7-tris(3-methylbut-2-en-1-yl)8-(4-methylpent-3-en-1-yl)bicyclo[3.3.1]non-3-ene-2,9-dione

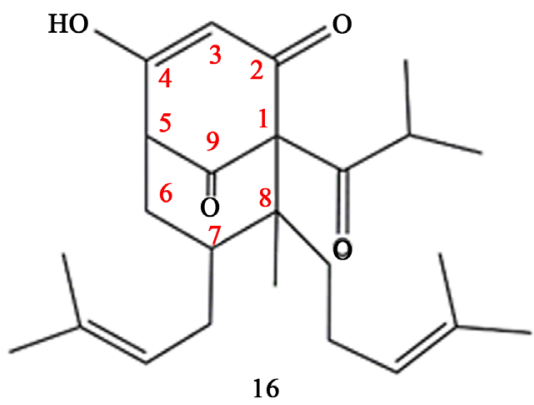

4-hydroxy-1-isobutyryl-8-methyl-7-(3-(methylbut-2-en-1-yl)-8-(4methylpent-3-en-1-yl)bicyclo[3.3.1]non-3-ene-2,9-dione

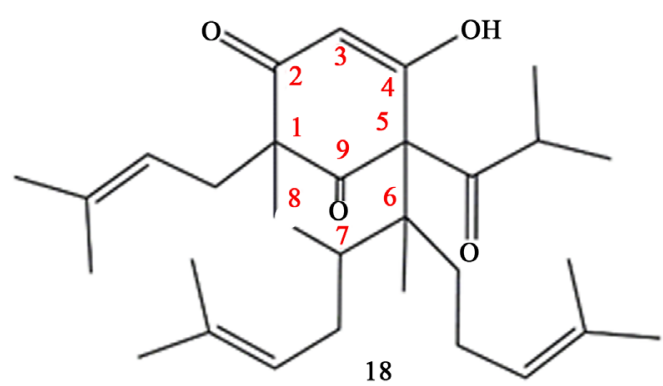

4-hydroxy-5-isobutyryl-6-methyl-1,7-bis (3-methylbut-2-en-1-yl)-6-(4-methylpent3-en-1-yl)bicyclo[3.3.1]non-3-ene-2,9-dione

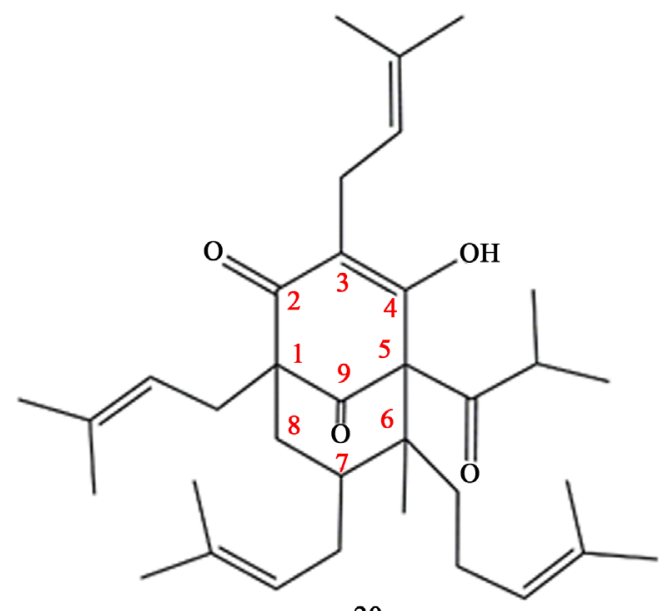

20

4-hydroxy-5-isobutyryl-6-methyl-1,3,7-tris(3-methylbut-2-en-1yl)-6-(4-methylpent-3-en-1-yl)bicyclo[3.3.1]non-3-ene-2,9-dione

Figure 5. Explanation for construction of names and numbering of $\mathrm{C}$ atoms for bicyclic compounds following IUPAC rules. Compound pairs 15 and 16,17 and 18, and 19 and 20 are differing isomer pairs; they are isomers in each of the pairs.

in the bicyclic system is confusing, and the C- 1 and C-5 positions were exchanged. For this reason, it could be expected that the chirality was also changed. However, it was overall not possible to comment confidently on the chirality of these carbons because the numbering of the carbon atoms compromised the relative chemistry of this substance [10]. 
Bystrov et al., 1975 ref. 6

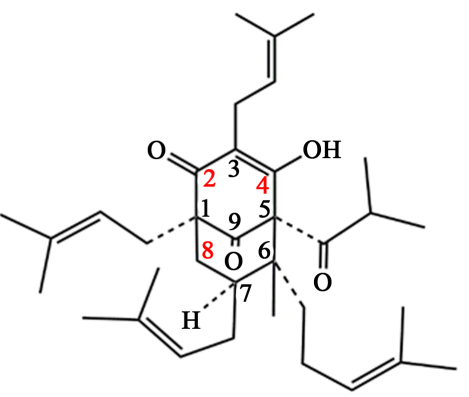

$(1 S, 5 R, 6 R, 7 S)$-4-hydroxy-5-isobutyryl-6-methyl-1,3,7-tris (3-methylbut-2-en-1-yl)-6-(4-methylpent3-en-1-yl)bicyclo[3.3.1]non-3-ene-2,9-dione
Bystrov et al., 1976 ref. 10

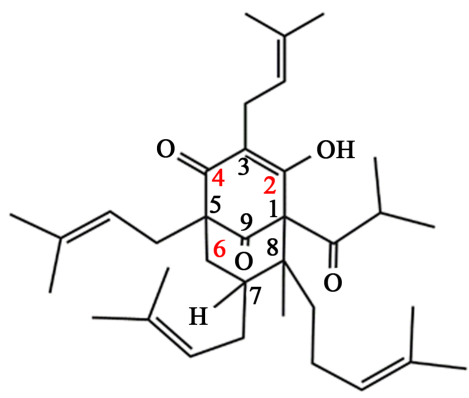

2-hydroxy-1-isobutyryl-8-methyl-3,5,7-tris (3-methylbut-2-en-1-yl)-8-(4-methylpent3-en-1-yl)bicyclo[3.3.1]non-3-ene4,9-dione

Bystrov et al., 1976 ref. 11

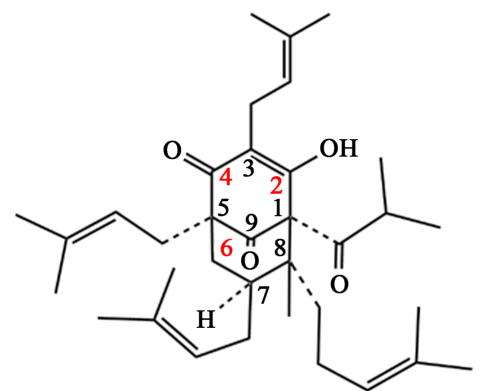

$(1 S, 5 R, 6 R, 7 S)$-4-hydroxy-5-isobutyryl-6-methyl-1,3,7-tris

(3-methylbut-2-en-1-yl)-6-(4-methylpent-

3-en-1-yl)bicyclo[3.3.1]non-3-ene-2,9-dione

Figure 6. The structures of hyperforin are reproduced from [6], [10], and [11] (The author of this paper added numbers in red and the names of the substances in black for better understanding). The numbering of the $\mathrm{C}$ atoms, published in [11], contradicts the IUPAC rules of numbering $\mathrm{C}$ atoms. The IUPAC name in red is constructed from the figure presented in [11].

In 1978, the same team published further information [24], in which an even stranger numbering of carbon atoms in a bicyclic system was used (see Figure 7). In addition, a team of Chinese authors presented a new numbering of carbon atoms in a bicyclic system in another publication on hyperforin (Figure 7) [25]. It appears that weakness in the knowledge of chemical nomenclature is common in some scientific communities.

\section{Conclusion}

The same team of authors was responsible for [6] [10] [11] and [24]. In [6], the relative and absolute stereochemistry of hyperforin contradicts the relative and absolute stereochemistry of hyperforin in [10] and [11]. In [6] [10] [11] and [24], the IUPAC rules for the numbering of $C$ atoms and the description of chirality were not followed. As long as [6] [10] and [11] continue to be cited and [6] [10] [11] or [24] are not withdrawn or corrected, it is absurd to state that Bystrov et al. defined the relative and absolute stereochemistry of hyperforin. The citing of these publications as the basis for the relative and absolute stereochemistry of 


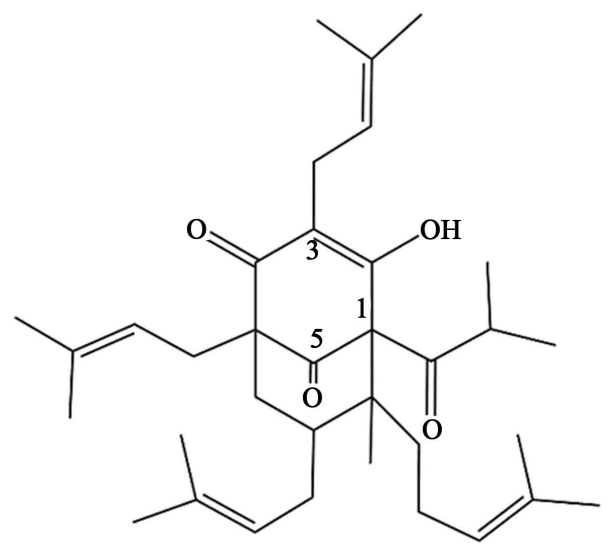

Bystrov et al., 1978 [24]

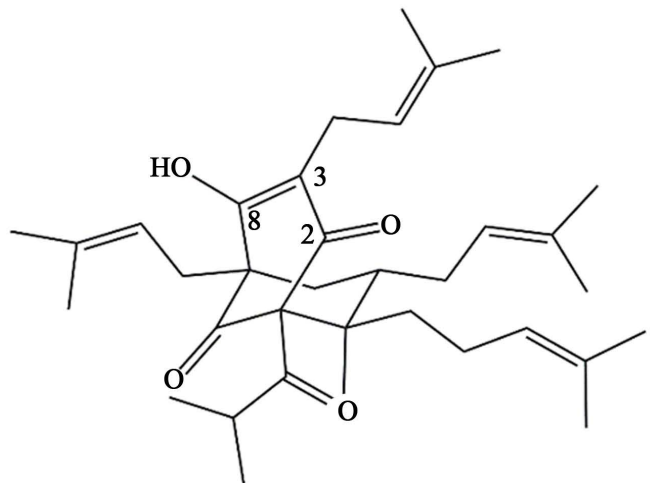

Ming De Shan et al., 2000 [25]

Figure 7. Numbering of C-atoms in the bicyclic system of hyperforin: (top) reproduced from [24] and (bottom) reproduced from [25].

hyperforin is incorrect. The value of the other publications by Bystrov et al. describing the determination of the relative and absolute stereochemistry of hyperforin is very limited, and this literature cannot be recommended as a basis for scientific work. Attempts to present Bystrov et al. as the discoverer of the relative and absolute stereochemistry of hyperforin in Wikipedia and in other publications at the expense of other authors are not ethical, and do not give prestige to the former USSR Academy of Sciences or to Wikipedia. This issue reflects the fact that Wikipedia is missing an Editor-in-Chief and qualified editorial staff.

\section{References}

[1] Osborn, E.M. (1943) On the Occurrence of Antibacterial Substances in Green Plants. The British Journal of Experimental Pathology, 24, 227-231.

[2] Volosovets, P.S. (1964) Microflora of Suppurative Wounds and the Quantitative Changes of the Microflora Due to the Effect of Treatment with Amanine and Novoimanine. Mikrobiolo-Gicheskii Zhurnal, 26, 60-65.

[3] Volosovets, P.S. (1986) The Effect of Novoimanine on the Course of Experimental Staphy lococcal Sepsis. Mikrobiolo-Gicheskii Zhurnal, 48, 60-64.

[4] Derbentseva, N.A., Volosovets, P.S. and Garagulya, A.D. (1970) Distribution of Novoimanin in Albino Rats after Administration by Various Means. Antibiotiki (Moscow), 15, 716-718. 
[5] Gurevich, A.I., Dobrynin, V.N., Kolosov, M.N., Popravko, S.A., Ryabova, I.D., Chernov, B.K., Derbentseva, N.A., Aizenman, B.E. and Garagulya, A.D. (1971) Hyperforin, an Antibiotic from Hypericum perforatum L. Antibiotiki Khimioterapi, 16, 510-513.

[6] Bystrov, N.S., Chernov, B.K., Dobrynin, V.N. and Kolosov, M.N. (1975) The Structure of Hyperforin. Tetrahedron Letters, 16, 2791-2794.

https://doi.org/10.1016/S0040-4039(00)75241-5

[7] Bystrov, N.S., Dobrynin, V.N., Kolosov, M.N., Popravko, S.A. and Chernov, B.K. (1978) Chemistry of Hyperforin. VI. General Chemical Characterization. Bioorganicheskaya Khimiya, 4, 791-797.

[8] Bystrov, N.S., Dobrynin, V.N., Kolosov, M.N., Popravko, S.A. and Chernov, B.K. (1978) VIII. Differentiation of the Side Chains. Bioorganicheskaya Khimiya, 4, 943947.

[9] Bystrov, N.S., Dobrynin, V.N., Kolosov, M.N., Popravko, S.A. and Chernov, B. (1978) Chemistry of Hyperforin. IX. The Structure of Hyperforin. Bioorganicheskaya Khimiya, 4, 948-955.

[10] Bystrov, N.S., Gupta, S.R., Dobrynin, V.N., Kolosov, M.N., Chernov, B.K., Chervin, I.I., Ya kovlev, G.I., Aizenman, B.E. and Derbentseva, N.A. (1976) Structure of the Antibiotic Hyperforin. Doklady Akademii Nauk SSSR, 226, 88-90.

[11] Bystrov, N.S., Dobrynin, V.N., Kolosov, M.N., Chernov, B.K., Chervin, I.I. and Yakovlev, G.I. (1976) Stereokhimiya Antibiotika Hyperforina. Doklady Akademii Nauk SSSR, 226, 338-341.

[12] Brondz, I. (1979) In: Antibiotikumet "Hyperforin" og andre innholdsstoffer i drogen Hypricum perforatum L. Thesis (Cand. Pharm.) University of Oslo, Oslo Norway. (In Norwegian)

[13] Brondz, I., Greibrokk, T., Groth, P.A. and Aasen, A.J. (1982) The Relative Stereochemistry of Hyperforin-An Antibiotic from Hypericum perforatum L. Tetrahedron Letters, 23, 1299-1300. https://doi.org/10.1016/S0040-4039(00)87088-4

[14] Brondz, I., Greibrokk, T. and Aasen, A.J. (1983) n-Alkanes of Hypericum perforatum: A Revision. Phytochemistry, 22, 295-296. https://doi.org/10.1016/S0031-9422(00)80110-7

[15] Brondz, I., Greibrokk, T. and Aasen, A.J. (1983) n-1-Alkohols of Hypericum perforatum. Journal of Natural Products, 46, 940-941. https://doi.org/10.1021/np50030a025

[16] Brondz, I., Greibrokk, T., Groth, P. and Aasen, A.J. (1983) The Absolute Configuration of Hyperforin, an Antibiotic from Hypericum perforatum L., Based on the Crystal Structure Determination of Its $p$-Bromobenzoate Ester. Acta Chemica Scandinavica, A37, 263-265. https://doi.org/10.3891/acta.chem.scand.37a-0263

[17] Brondz, I. (1986) Lecture Entitled: "The Influence of Hyperforin on Phagocytosis of E. coli by Human Polymorphonuclear Neutrophils In Vitro". Symposium Norlændskainfektions sjkdomar, Vårmøtet i Sundsvall, 14-15 Maj 1986. https://www.researchgate.net/publication/233795016

[18] Brondz, I. (1987) Influence of Hyperforin upon Phagocytic Functions in Human Polymorphonuclear Leucocytes. 4th International Conference on Chemistry and Biotechnology of Biological Active Natural Products, (Budapest) Hungary, 10-14 August 1987, Abstract B-15, 119.

[19] Brondz, I. (2012) Enhancement of the Immunity in AIDS and Other Immunocompromised Patients by Hyperforin an Antibiotic from Hypericum perforatum L. 2 nd ARIP European Conference on Antimicrobial Resistance \& Infection Prevention, 
Vilnius, 4-5 October 2012, Abstract 12, 60. In: Oficialus Lietuvos Bendrosios Praktikos Gydytojų Kolegijos Leidinys, No. 7, 1392-3218.

[20] Brondz, I. and Brondz, A. (2012) Recent Enhancement of the Immunity in AIDS and Other Immunocompromised Patients by Hyperforin an Antibiotic from Hypericum perforatum L. (In Vitro Model) Part I. Journal of Biophysical Chemistry, 3, 304-310. https://doi.org/10.4236/jbpc.2012.34037

[21] Brondz, I. (2016) Super Antibiotics, Part I. Hyperforin. Voice of the Publisher, 2, 19-27. https://doi.org/10.4236/vp.2016.24004

[22] Brondz, I. (2016) Super Antibiotics, Part II. Hyperforin, Mass Spectroscopy (MS) and Gas Chromatography-Mass Spectrometry (GC-MS), Evidence of Permeability of the Blood-Testis Barrier (BTB) and the Blood-Brain Barrier (BBB) to Hyperforin. International Journal of Analytical Mass Spectrometry and Chromatography, 4, 66-73. https://doi.org/10.4236/ijamsc.2016.44007

[23] Brondz, I. (2013) Analytical Methods in Quality Control of Scientific Publications Part II the Authors', Reviewers', Editors' Responsibility and the Publishers' Authority, International Journal of Analytical Mass Spectrometry and Chromatography, 1, 81-89. https://doi.org/10.4236/ijamsc.2013.12010

[24] Bystrov, N.S., Dobrynin, V.N., Kolosov, M.N. and Chernov, B.K. (1978) Cemistry of Hyperforin. VII. The Structure of the Tetracarbonyl System. Bioorganicheskaya Khimiya, 4, 798-805.

[25] Shan, M.D., Hu, L.H. and Chen, Z.L. (2000) Pyrohyperforin, A New Prenylated Phloroglucinol from Hypericum perforatum. Chinese Chemical Letters, 11, 701704.

\section{Scientific Research Publishing}

\section{Submit or recommend next manuscript to SCIRP and we will provide best service for you:}

Accepting pre-submission inquiries through Email, Facebook, LinkedIn, Twitter, etc. A wide selection of journals (inclusive of 9 subjects, more than 200 journals) Providing 24-hour high-quality service User-friendly online submission system Fair and swift peer-review system Efficient typesetting and proofreading procedure Display of the result of downloads and visits, as well as the number of cited articles Maximum dissemination of your research work

Submit your manuscript at: http://papersubmission.scirp.org/ Or contact vp@scirp.org 